\title{
Stabilising and Trimming 3D Woven Fabrics for Composite Preforming Applications
}

\author{
Alice E. Snape ${ }^{1}$ (D) - Jody L. Turner ${ }^{1}$ • \\ Hassan M. El-Dessouky ${ }^{1,2} \cdot$ Mohamed N. Saleh $^{1}$. \\ Hannah Tew ${ }^{1} \cdot$ Richard J. Scaife ${ }^{1}$
}

Received: 2 May 2018 / Accepted: 26 June 2018 / Published online: 19 July 2018

(C) The Author(s) 2018

\begin{abstract}
The work presented here focusses on the developments in the stabilising and trimming of 3D woven preforms. Dry fibre preforms are notoriously difficult to trim; once a fabric is cut, it loses its edge stability and consequently the fabric frays. The result is an unstable fabric which can easily be displaced/ distorted prior to composite manufacturing. In this work, three stabilisation and three trimming techniques were investigated. Of the stabilisation techniques these included powder binder, thermoplastic binder yarn (activated to give fabric stabilization); and polyester stitching. The stabilised fabrics were trimmed to near-net-shape using different trimming techniques. The trimming techniques investigated were laser, clicker press and ultrasonic knife. Each stabilisation method was trialled with each trimming method to assess the most suitable combination. The assessment of quality and suitability was made by observing the level of stabilisation, amount of fraying fibres, quality of the cut, ease of application and repeatability of the process. This paper details the assessments made for each combination alongside practical application conclusions. The key findings were; cutting by means of a laser is capable of sealing the fabric edges, producing high edge quality. Stitching as a method of stabilising is not sufficient in preventing fibres from moving during the cutting process, hence producing an unclean cut.
\end{abstract}

Keywords Stabilisation · Trimming $\cdot 3 \mathrm{D}$ woven fabrics $\cdot$ Carbon fibre

Alice E. Snape

a.e.snape@sheffield.ac.uk

Jody L. Turner

j.l.turner@sheffield.ac.uk

1 AMRC with Boeing, Composite Centre, University of Sheffield, Rotherham S60 5TZ, UK

2 Physics Department, Mansoura University, Mansoura, Egypt 


\section{Introduction}

Dry fabrics have very different cutting characteristics to pre-impregnated (prepreg) materials which are currently widely used in the composites industry [1]. Prepreg materials have the added benefit of being inherently stabilised by the resin preapplied to the fabric, hence fabric fraying is not a significant problem. However, the limitations of using prepreg materials are well known; they require storage and have a limited shelf life, material costs are higher; typical processing is with an autoclave which is expensive, slow to operate and limited in size; the tooling and core materials are required to withstand curing temperatures and pressures [2]. The components manufactured from prepregs are typically 2D in architecture, offering poor out-ofplane mechanical properties [3-5]. This can be overcome by using a 3D woven material whereby the through thickness binder yarn has been found to have a significant effect on improving the out of plane mechanical properties [4, 6-10], with the additional advantage of not having the aforementioned issues associated with prepreg processing.

The use of dry fibre preforms, especially woven preforms in the composite industry, is increasing [11]. 3D woven fabrics also offer the opportunity for one piece preforms, a reduction in layup time and manufacturing costs [3]. However, at present $3 \mathrm{D}$ woven fabrics do not currently originate with the stabilising resin readily applied and as a result dry carbon fibre fabrics are notoriously difficult to cut or trim to shape. Dry fabrics are considered unstable, because the cutting force results in fibres being bent and displaced [12]. Once cut, a fabric loses its edge stability and there is a high risk of the fabric fraying. Fabric fraying occurs when tows on the edge of the fabric become loose and detach from the fabric. This is a significant problem with $2 \mathrm{D}$ dry fabrics but is exacerbated in $3 \mathrm{D}$ fabrics where there are multiple layers present and the problem is amplified over these multiple layers. Therefore, fabric stabilisation prior to trimming needs to be addressed in order to reduce fabric distortion during preform manipulation for 3D woven fabrics.

Typical cutting methods for 2D fabrics are a drag knife and a rotary knife. These may not be optimal because the physical contact between the cutting tool and fabric creates damage to the cut edge, with thicker 3D structures the damage is intensified [12].

A preliminary study conducted at the AMRC identified powder binder, a thermoplastic (TP) binder yarn and stitching as methods of interest for stabilising 3D woven fabrics. In the same study, an ultrasonic knife, clicker press and laser were identified as methods for trimming the fabrics.

Powder binder is widely used to stabilise 2D fabrics [13]. However the applicability to only apply to the outer surfaces of a fabric could be a limitation for 3D fabrics as it may provide limited depth penetration. Whereas TP binder yarns (which are co-woven into the fabric) could provide stabilisation throughout the whole woven structure (through thickness, length and width). Similarly stitching provides a through thickness stability, but is focusses at the edge rather than throughout the entire fabric.

The laser provides contact free cutting, but whilst cutting, high temperatures are generated which scorches/burns the edge of the fabric, forming sealed edges [12, 14]. Alternatively the clicker press and ultrasonic knife require contact between the tool and fabric to create the cut. The direct contact between the tool and the fabric can result in additional damage to the fabric from disruption of the cutting tool. The ultrasonic knife uses high frequency vibrations, resulting in minimal contact between the tool and fabric [15]. In contrast, the clicker press 
requires complete contact between the tool and fabric. Unlike a drag knife or rotary knife where the knife is pulled along the surface of the fabric, the tool is positioned directly on top of the fabric and pressure is applied to the tool from above to stamp out the fabric.

To assess the effectiveness of each stabilisation method combined with each trimming method, trials are carried out on each combination and assessed by means of fray analysis and microscopy.

\section{Material}

Each trial was conducted on identical samples of fabric manufactured in the scope of a larger programme focused on the development of 3D woven preforms for use in automotive applications. A more in-depth description of the design and manufacture of this $3 \mathrm{D}$ woven preform is given by El-Dessouky et al. [16]. The samples were taken from the same batch of 3D woven, five layer multilayer satin fabric. The weave architecture is schematically depicted in Fig. 1. The material used to produce the fabric was Toray T700 SC sized $12 \mathrm{~K}$ carbon fibre. The fabric was produced on a Dornier dobby weaving machine. The density in the warp and weft directions was even with 12.66 tows/cm; yielding a balanced fabric of $3 \mathrm{~mm}$ thick. The fabric consisted of five layers of satin weave which are all inter-connected and woven simultaneously.

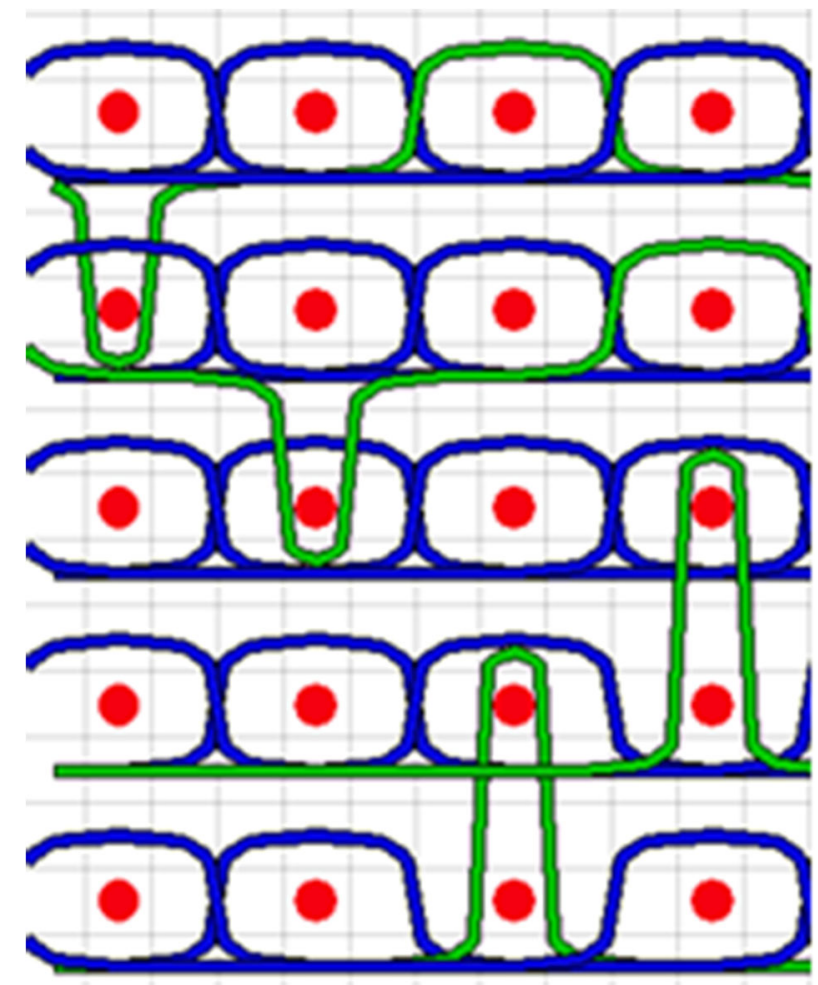

Fig. 1 Image of the through thickness of a five layer multilayer satin 


\section{Stabilisation and Trimming Methodologies}

Three stabilisation techniques (powder binder, TP yarn and stitching) and three trimming techniques (laser, clicker press and ultrasonic knife) were trialled in this study.

To ensure that the quality of cut was only affected by the unique combination of stabilising/trimming technique used, identical cuts were performed on every sample, at the same orientation on the fabric. These identical cuts incorporated linear sections, as well as curved/radial sections. The cut created each time is shown in Fig. 2, both linear and radial features were incorporated into the cut such that observations could be made regarding the suitability of a technique to common geometrical features. For each stabilisation and trimming combination, three samples were produced per combination. In the case of the ultrasonic knife and clicker press die, where tool wear may provide differences in cuts, new tools were used.

\subsection{Stabilisation Techniques}

The powder binder used was Epikote EP 05390. With no automated application technique available, a manual technique was used, aiming to distribute the powder evenly. $18 \mathrm{~g}$ of powder binder was applied to both the top and bottom fabric surfaces, totalling $36 \mathrm{~g}$. Consequently the powder added $2.5 \%$ to the preforms weight. To activate the binder, the fabric was placed within a heated press, between 2 platens of $1 \mathrm{~m} \times 1.5 \mathrm{~m}$ in size. The platens

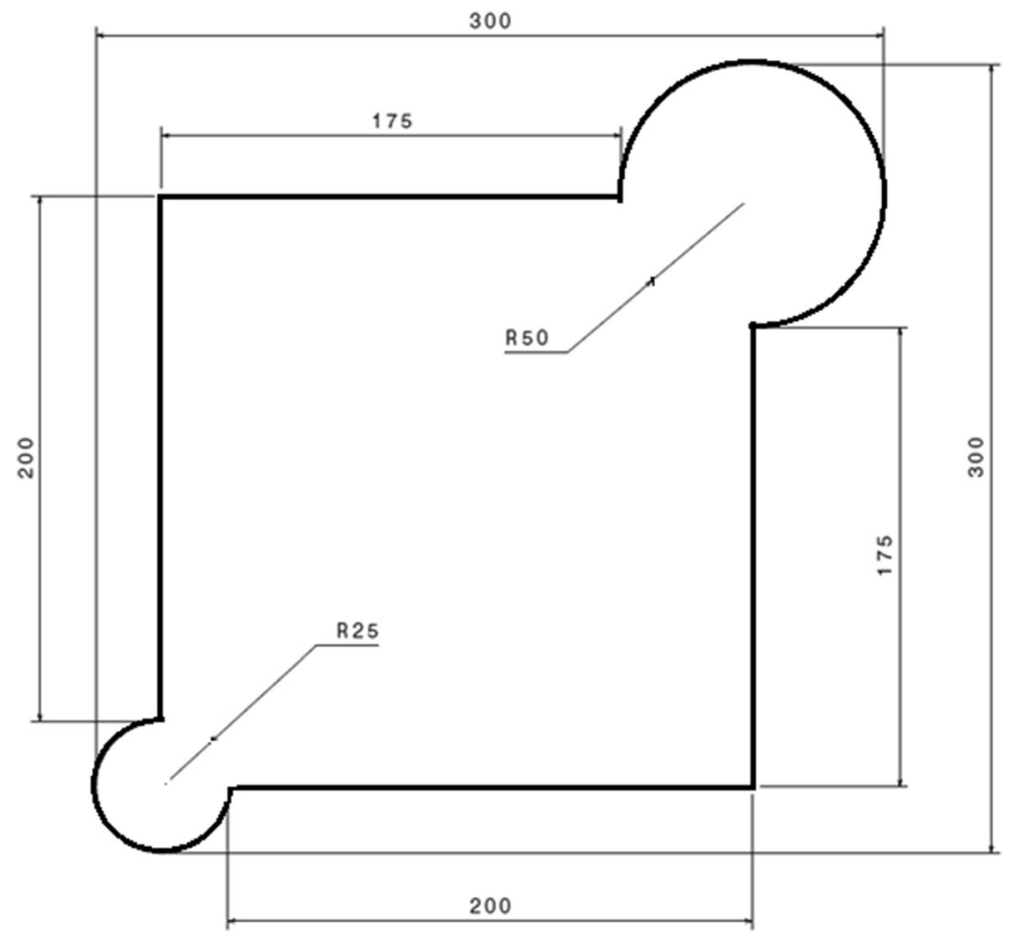

Fig. 2 Shape for the trimming trials 
and fabric were heated at $3{ }^{\circ} \mathrm{C} / \mathrm{min}$ to $100{ }^{\circ} \mathrm{C}$. The press was held at $100{ }^{\circ} \mathrm{C}$ for $10 \mathrm{~min}$, then forced cooled to $40{ }^{\circ} \mathrm{C}$ prior to fabric removal. Figure 3 shows the powder binder before activation and after activation.

The TP yarn was co-woven into the fabric with a ratio of one TP yarn to one carbon tow, in the weft direction. The density in the weft direction was increased to $25 \mathrm{picks} / \mathrm{cm}$ to compensate for the additional TP yarn. The TP made up 5.5\% of the preforms weight. To activate the TP the fabric was placed within a heated press between two platens. The platens and fabric were heated $3{ }^{\circ} \mathrm{C} / \mathrm{min}$ to $175^{\circ} \mathrm{C}$ for $10 \mathrm{~min}$. The press was force cooled to $70{ }^{\circ} \mathrm{C}$ prior to removing the fabric. Figure 4 shows the TP yarn co-woven into the fabric both prior to and after activation.

The fabrics were stitched on a flatbed sewing machine by a human operator and were stitched approximately $2 \mathrm{~mm}$ from the cutting edge as shown in Fig. 5. During the trimming trials it was necessary for the cutting method to be aligned with the stitching to ensure the fabric was cut on the outside of the stitching. There was some difficulty in aligning the cutting tool to the stitched profile and in some places the stitching was intercepted or completely misaligned. To improve the accuracy of the stitching a robot stitching head would be beneficial and could create marker points to align with the cutting method. This was out of scope for this work, but will be investigated further by the authors in the future.

\subsection{Trimming Techniques}

A Ytterbium YLS 16000 laser system attached to a robot was used with a speed of $30 \mathrm{~mm} / \mathrm{min}$. This system did not require a cutting tool, so there was no concern with tool wear. To avoid inhalation of potentially toxic fumes, the trials were carried out in an air-locked room with extraction.

The clicker press is an alternative to hydraulic cutting presses. A die was specifically created to the template, as shown in Fig. 6b. The die is positioned on the fabric, where the press applies pressure to the die and consequently the fabric is stamped out. The samples were cut out by DCR machines Ltd.

The ultrasonic knife was embedded in an Assyst Bullmer CNC cutting machine, with a cutting speed of $5 \mathrm{~m} / \mathrm{min}$ at a frequency of $20 \mathrm{kHz}$. The ultrasonic knife is shown in Fig. 7.

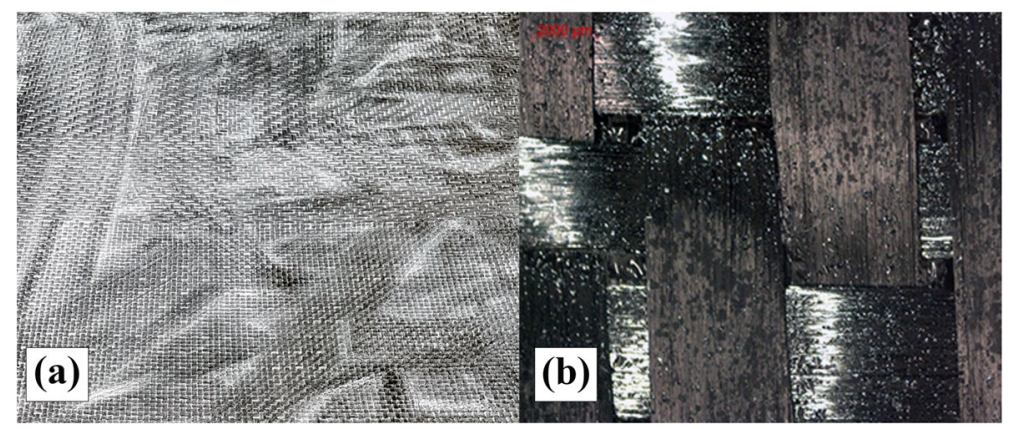

Fig. 3 a Powder binder before activation and $\mathbf{b}$ after activation 


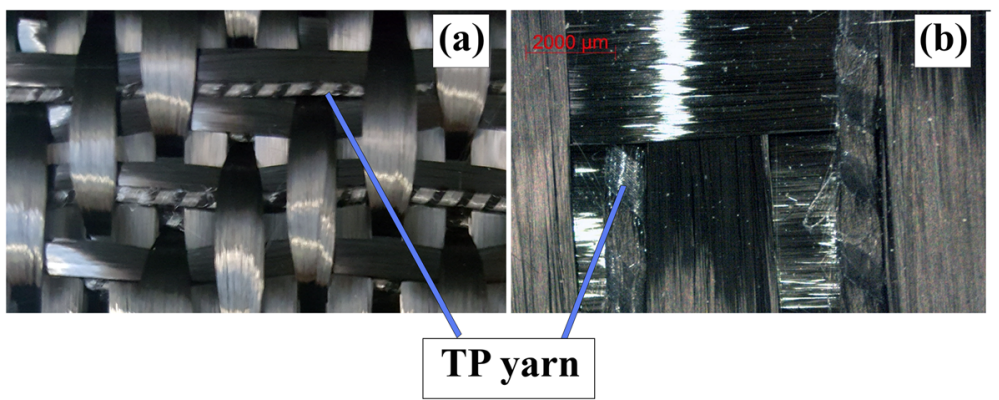

Fig. 4 a TP yarn before activation and $\mathbf{b}$ after activation

\section{Results and Discussion}

The objective of the project was to find suitable methods of stabilising and trimming 3D woven fabrics to produce high quality fabric edges. Subsequently to cutting the fabrics, the cut edges were analysed to determine the quantity of outlier fibre and quality of the cut using optical microscopy and numerical fray analysis developed in house.

\subsection{Fray Analysis}

After cutting, a template of the exact shape was placed on top of the cut out shape and photographed from directly above, as shown in Fig. 8. Any fibres beyond the template were either frayed fibres, displaced fibres or as a result of a problem with the cutting accuracy. Any fibre beyond the template could generate problems with future processing, for example placing the preform in an RTM mould.

Using image processing software (namely Image J), the photographs were converted to a binary image, consisting of white and black pixels, as shown in Fig. 9. The white template, placed on top of the fabric, automatically became white, and any fibres within the image, were highlighted black. The black pixels are assumed to be outlier fibre, caused by the cutting technique. The number of black pixels within the image were taken as a representative figure of damage caused by the cutting process and converted to area $\left(\mathrm{mm}^{2}\right)$.

Figure 10 shows a graph showing the average of the three results in each of the nine cases and the error bars represent the standard deviation. The graph shows that the laser

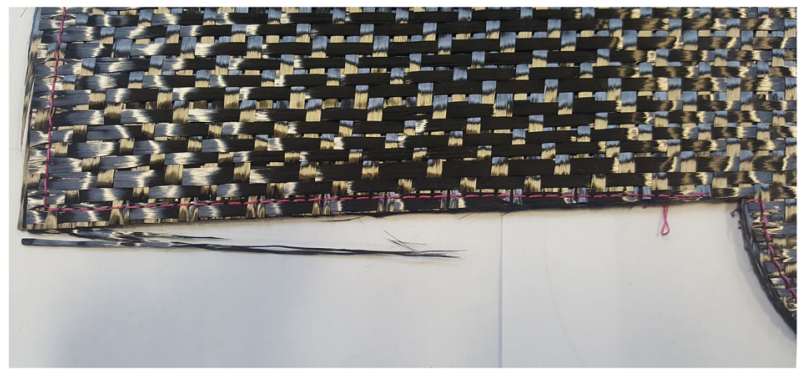

Fig. 5 Image of stitching on the fabric edge 


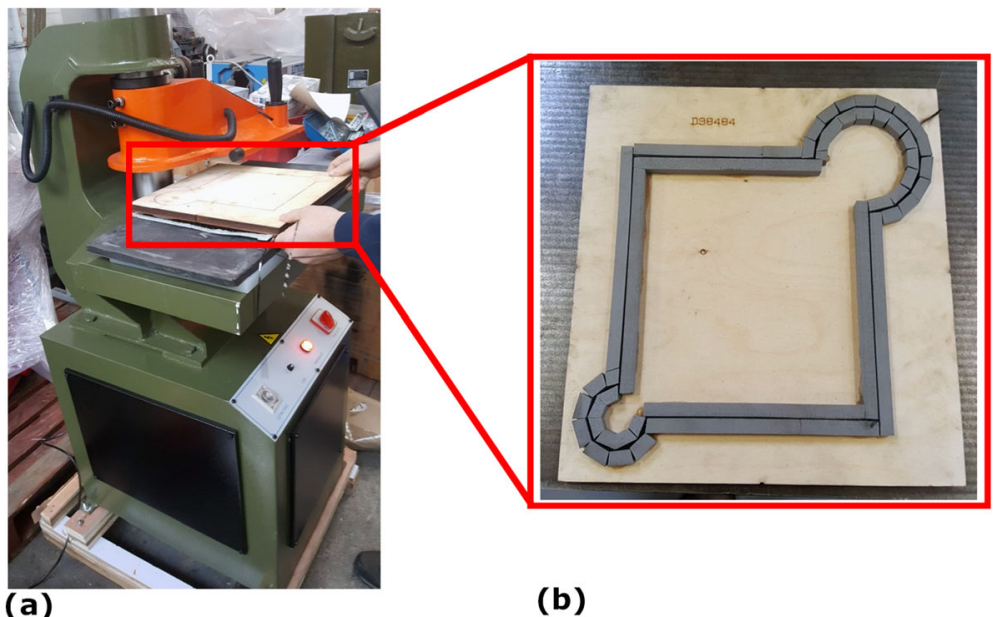

Fig. 6 Images of $\mathbf{a}$ the clicker press and $\mathbf{b}$ the cutting die

cutting technique routinely produced the least amount of outlier fibre. Similarly the clicker press with the TP yarn produced low levels of fibre outlier whereas levels were higher for the TP yarn with the ultrasonic knife. Additionally the fabrics stabilised using stitching had the highest amount of outlier fibre, with the exception of the laser cutting technique. Finally, the ultrasonic knife produced similar amounts of fibre outlier for the powder and TP yarn stabilisation techniques.

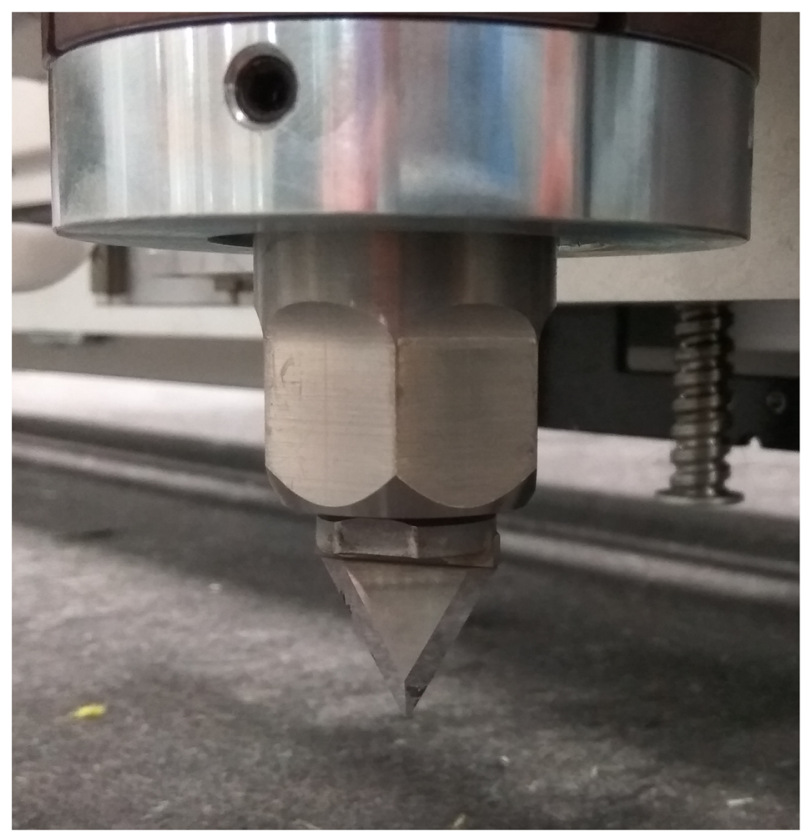

Fig. 7 Image of the ultrasonic Knife 


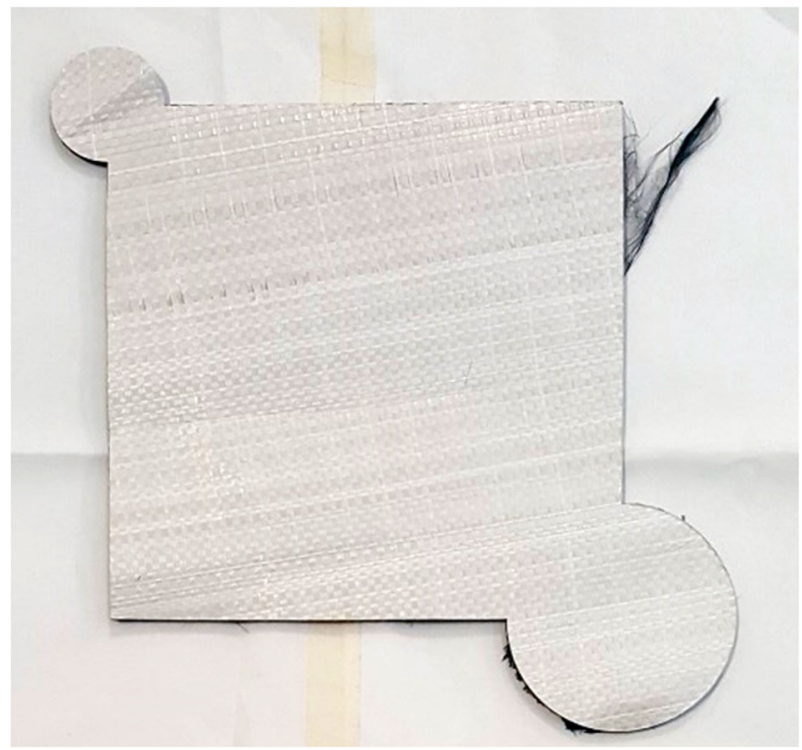

Fig. 8 Image of the photography set-up

\subsection{Microscopy}

The trimmed edges were investigated in greater detail, using a Zeiss AxioCam ERc $5 \mathrm{~s}$ microscope with $\times 6.5$ magnification. The optical images allow an appreciation for filament disruption as well as tow disruption.

\subsection{Linear Edges}

Figure 11 shows example optical images of the linear edges; there is one image for each stabilisation and trimming combination. These images demonstrate that the laser in all stabilisation techniques sealed the edge of the fabric whilst cutting by fusing the fibre ends with the heat produced during cutting. The sealed edges have produced a neat edge and
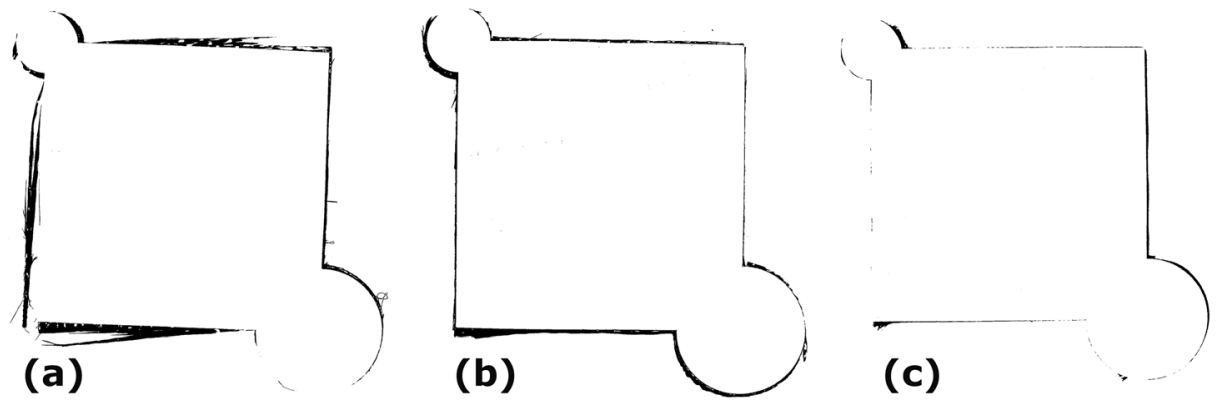

Fig. 9 Example images of binary photographs; a stitching with clicker press, b powder with ultrasonic knife and c TP yarn with laser 


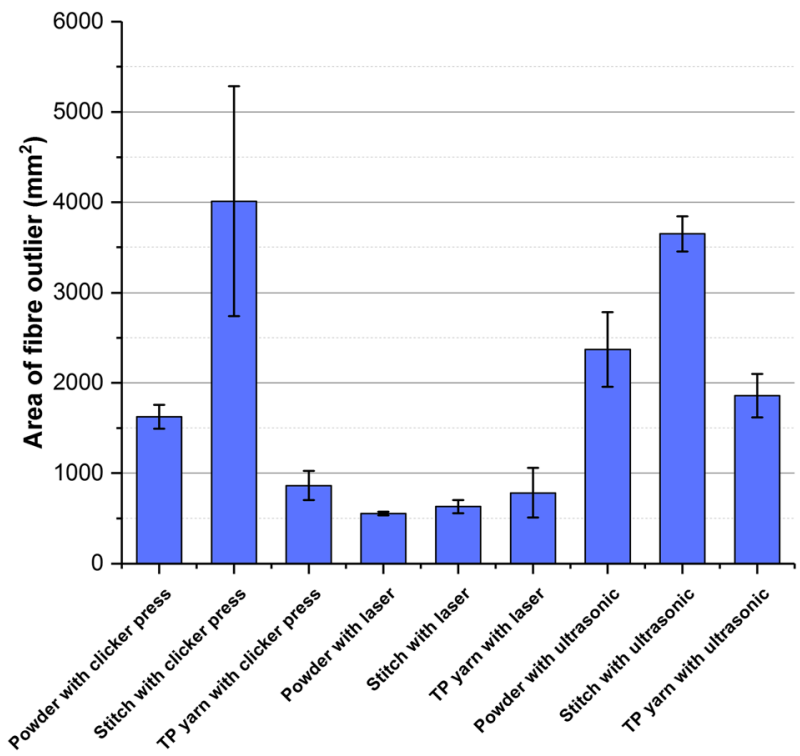

Fig. 10 Graph of the average area of the black "outlier fibre" in $\mathrm{mm}^{2}$

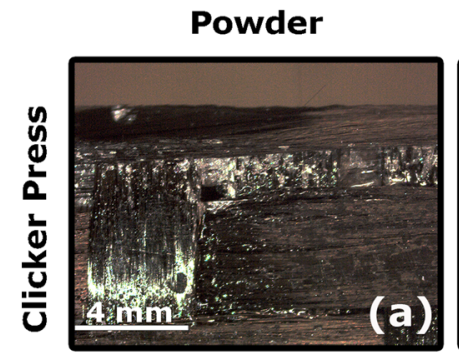

Thermoplastic
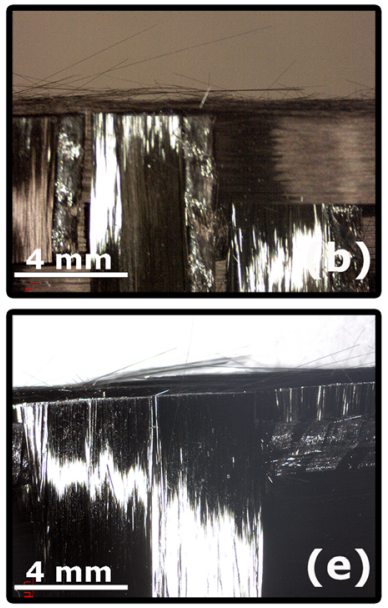

(d)

$4 \mathrm{~mm}$
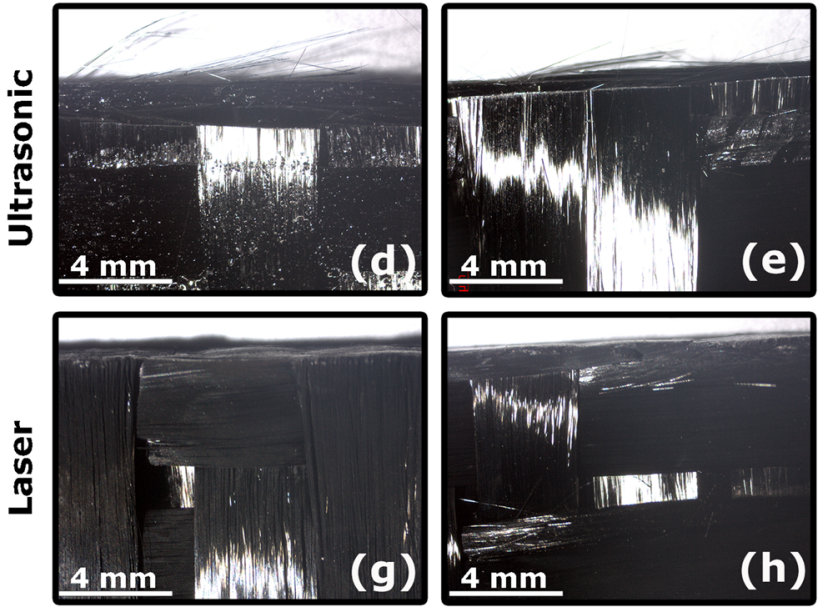
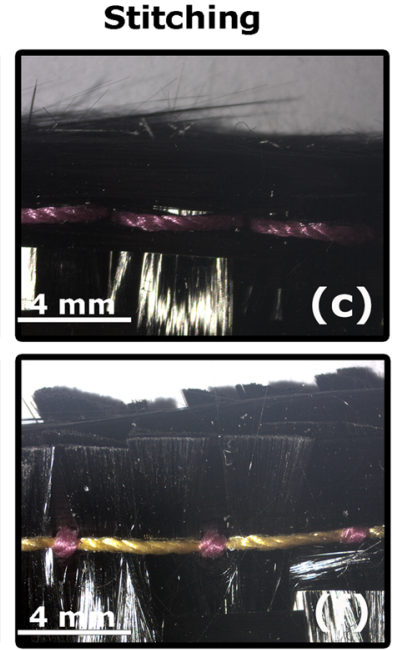

Fig. 11 Optical images showing fabric edge quality on linear edges

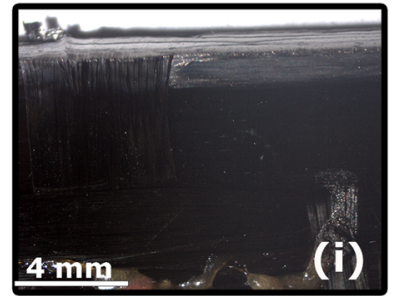

Fig. 11 Optical inages showing fabic edge quatiy on linear edges 
produced low amounts of outlier fibre as seen in Fig. 10. A.N, Fuchs et al. reports this grey colour to be a heat affected zone, caused by smoldering [12], this is evident more so with the fabric that was stitched. The effect of the heat affected zone on the composites final properties is still unclear but the technique appears promising for creating neat edges and preventing fibre pulling away from the edges. However, the stitching looks to have had little effect at stabilising the fabric as the heat from the laser has melted the polyester stitching.

In Fig. 11, photographs a-e, observe that the fabric is fully cut but fibres are pulling away from the cut edge. Where the parallel tows have been cut in the middle of the tow, this appears to have contributed to the fibre fray. Where the cut fibres have started to stray away from the cut edge with increased handling it is highly likely the number of stray fibre will escalate having a detrimental effect on the edge quality.

In the case of photograph in Fig. 11, the stitching appears to have provided very little edge stabilisation, as the cut edge appears to be very uneven. The lack of stabilisation has been identified to cause movement within the tows during cutting process, hence producing an uneven cut.

\subsection{Radial Edges}

Figure 12 shows examples of the radial cuts. The laser had a similar effect on cutting the radius of the powder and stitched fabric to the linear edge by sealing the edge. However, the TP stabilised fabric is less of a clean cut. The TP stabilised fabric is slightly thicker due to the additional yarn. The microscopy image shows the bottom layer to have had difficulty cutting,
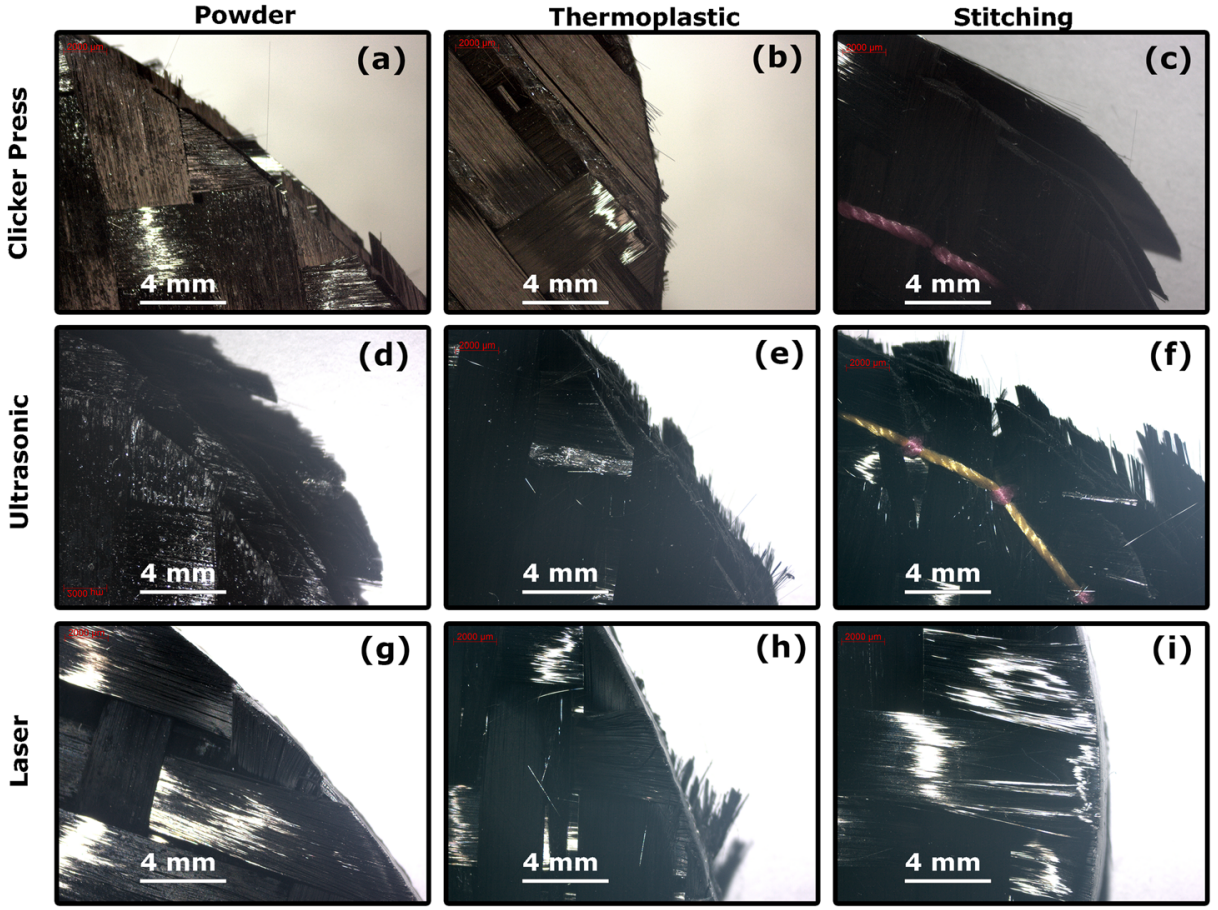

Fig. 12 Optical images showing fabric edge quality on radial edges 
possibly due to the thicker fabric and the laser did not have enough power to produce a clean and sealed edge.

Photographs a, $\mathrm{c}-\mathrm{f}$ in Fig. 12 showed the cut to be staggered between the layers, creating an uneven edge. It is assumed that this occurred from either the layers moving whilst cutting or prior to cutting the fabric was positioned unnaturally and afterwards the fabrics have relaxed into a natural state creating a staggered edge. Of these staggered edges the ultrasonic knife with stitching appears to be the worst, indicating that the stitching had very little effect at stabilising the edge of the fabric.

Finally the TP yarn cut with the clicker press shows a comparatively even edge with only a small amount of fibre fray. This agrees with Fig. 10 whereby the TP yarn and clicker press had a low amount of outlier fibre.

\section{Conclusion}

This paper set out to assess stabilisation and trimming methods for use on 3D woven fabrics. Throughout this study, some new analytical techniques haves been used to asses cut quality (on linear and radial edges) and provide discernment between different stabilisation and trimming techniques. In summary, the laser was capable of sealing the fabric edges, producing a high edge quality, thereby resulting in minimal outlying fibres. A secondary effect of using the laser was the edge had a heat affected zone. The effect of this zone on the final composite properties is unknown and further work is recommended to address this. On the other hand, if the final composite is not net edge, it will require further machining, in which case the heat affected zone would be removed, hence not affecting the final composites properties. Stitching the fabric had little effect at stabilising the edge of the fabric resulting in the movement of tows during the cutting process. Moreover there was difficulty in aligning the stitching to the trimming process. In conclusion stitching is not an ideal method for stabilising 3D woven fabric. The powder binder was effective at stabilising the $3 \mathrm{~mm}, 3 \mathrm{D}$ woven fabric used in this study. However in this study, the depth of penetration was not assessed. Hence its suitability for thicker 3D woven fabrics is still unknown. Further work is recommended to address this. In the case of the ultrasonic knife and clicker press, a higher quality of cut was achieved with the linear cut in comparison to radius cut whereby the layers are assumed to have moved during or after cutting resulting in an uneven edge.

Acknowledgements The authors would like to thank the UK Catapult and project partners: National Composite Centre (NCC), Warwick Manufacturing Group (WMG) and Manufacturing Technology Centre (MTC).

Open Access This article is distributed under the terms of the Creative Commons Attribution 4.0 International License (http://creativecommons.org/licenses/by/4.0/), which permits unrestricted use, distribution, and reproduction in any medium, provided you give appropriate credit to the original author(s) and the source, provide a link to the Creative Commons license, and indicate if changes were made.

\section{References}

1. Costa, M.L., Botelho, E.C., De Paiva, J.M.F., Rezende, M.C.: Characterization of cure of carbon/epoxy prepreg used in aerospace field. Mater. Res. 8, 317-322 (2005) 
2. Mazumdar, S.K.: Introduction. In: Composite Manufacturing: Materials, Product and Process Engineering. CH.6, Boca Raton, CRC Press (2002)

3. Mouritz, A.P., Bannister, M.K., Falzon, P.J., Leong, K.H.: Review of applications for advanced threedimensional fibre textile composites. Compos. Part A. 30, 1445-1461 (1999)

4. Stig, F., Hallström, S.: Assessment of the mechanical properties of a new 3D woven fibre composite material. Compos. Sci. Technol. 69, 1686-1692 (2009)

5. Saleh, M.N., Yudhanto, A., Potluri, P., Lubineau, G., Soutis, C.: Characterising the loading direction sensitivity of 3D woven composites: effect of z-binder architecture. Compos. Part A: Appl. Sci. Manuf. 90, 577-588 (2016)

6. Redman, C., Bayraktar, H., Mcclain, M.: Curved beam test behavior of 3D woven composites. In: SAMPE Seattle, WA, June 2-5, (2014)

7. Luo, Y., Lv, L., Sun, B., Qiu, Y., Gu, B.: Transverse impact behavior and energy absorption of threedimensional orthogonal hybrid woven composites. Compos. Struct. 81, 202-209 (2007)

8. Gerlach, R., Siviour, C.R., Wiegand, J., Petrinic, N.: In-plane and through-thickness properties, failure modes, damage and delamination in $3 \mathrm{D}$ woven carbon fibre composites subjected to impact loading. Compos. Sci. Technol. 72, 397-411 (2012)

9. El-Dessouky, H.M., Snape, A.E., Turner, J.L., Saleh, M.N., Tew, H., Scaife, R.J.: 3D weaving for advanced composite manufacturing: from research to reality. Sampe 2017. (2017)

10. Saleh, M.N., Soutis, C.: Recent advancements in mechanical characterisation of 3D woven composites. Mech. Adv. Mater. Mod. Process. 3:(12), (2017)

11. Potluri, P., Sharif, T., Jetavat, D.: Robotic approach to textile preforming for composites. Indian J. Fibre Text. Res. 33, 333-338 (2008)

12. Fuchs, A.N., Schoeberl, M., Tremmer, J., Zaeh, M.F.: Laser cutting of carbon fiber fabrics. Phys. Procedia. 41, 372-380 (2013)

13. Aranda, S., Klunker, F., Ziegmann, G.: Influence of the binding system on the compaction behaviour of Ncf carbon fibre. 18Th Int. Conf. Compos. Mater. 1-6 (2011)

14. Bliedtner, J., Remdt, S., Müller, H., Petrich, A.: Laser cutting of carbon Fibres. Laser Tech. J. 10, 45-48 (2013)

15. Viļumsone-Nemes, I.: 9 - automated cutting of textile materials. In: Industrial Cutting of Textile Materials. pp. 104-127 (2012)

16. El-Dessouky, H.M., Snape, A.E., Tew, H., Scaife, R.J., Modi, D.K., Kendall, K., McHugh, C.: Design, weaving and manufacture of a large $3 \mathrm{~d}$ composite structure for automotive applications. In: 7th World Conference 3D Fabrics and their Applications. 3D Fabrics and their Applications (2016) 